\title{
EL MARIHUANO Y SU ESTIGMA EN CIUDAD JUÁREZ. UNA LECTURA FOTOGRÁFICA
}

FRANCISCO SERVÍN ROMERO ${ }^{1}$

RUTILIO GARCÍA PEREYRA ${ }^{2}$

\section{RESUMEN}

1 l objetivo del siguiente texto es analizar el estigma del marihuano que se ha constituido en Ciudad Juárez. El análisis se realiza mediante la intervención urbana a través de un proceso creativo de fotografía. El enfoque teórico es sociológico y antropológico. La técnica documental es a través de colocación de fotografías de personas fumando marihuana en distintos muros de la ciudad para que el transeúnte las observe y las intervenga, el registro es con video-fotografía.

Palabras clave: intervención urbana, documental, fotografía, marihuano, Ciudad Juárez. 


\begin{abstract}
The objective of the following text is to analyze the stigma that marijuana has created in Ciudad Juárez. The analysis is carried out through urban intervention through a creative photography process. The theoretical approach is sociological and anthropological. The documentary technique is through the placement of photographs of people smoking marijuana on different walls of the city for the passer-by to observe and intervene, the registration is with video and photography.
\end{abstract}

Key words: urban intervention, documentary, photography, marijuana, Ciudad Juárez.

\title{
INTRODUCCIÓN
}

Como fotógrafos hay que estar conscientes de que lo que capturamos con nuestra cámara depende de nuestra sensibilidad con nuestro mundo;

...la fotografía y sociología son piezas fundamentales de la constitución misma de la sociedad industrial, no por su capacidad de incidencia en la producción o su influencia en la economía, sino porque introducen formas de conocer y explorar el mundo e ideas para comprenderlo (Suárez, 2008: 13-14).

No solo se captura por medio del lente, además es fundamental cómo percibimos como fotógrafos. Sin duda, también es importante conocer lo que está detrás de la fotografía-objeto para entender de mejor manera cómo es la aproximación de la persona que se encuentra detrás de la cámara, porque "podemos utilizar la fotografía para reproducir con precisión la naturaleza, pero no por ello debemos creer que esta es la finalidad última de la fotografía” (Graff en Fontcuberta, 2016: 161). La fotografía no muestra en sí la realidad, sino algo que pasó frente de la cámara, alguien observó la escena y la registró en su tiro fotográfico. Sin embargo, del acto 
fotográfico surge la siguiente pregunta: ¿qué es lo que observó y qué quiere decir su fotografía más allá de lo común?

Es frecuente la práctica mimética en la fotografía e incluso "se sigue discutiendo si la fotografía es o no es arte, y no se discute si el fotógrafo es artista o artesano" (Catalá, citado por Fontcuberta, 2016: 180). Por ejemplo, es común observar que fotógrafos quieren imitar a la pintura, quizá en parte porque "los manuales de fotografía son muy nocivos al implantar límites basados en la estética o reglas artísticas" (Graff citado por Fontcuberta, 2016: 161). Los manuales enseñan que el acto fotográfico se remite a reglas de encuadre y luces, pero dicen poco o nada sobre cómo vivir la escena, cómo ver la vida, no dan cuenta de la sensibilidad de cada fotógrafo y cómo interfiere en el proceso creativo. Cada fotógrafo le da sentido al caos de la vida y en cada uno de sus clicks se explora lo cotidiano.

La vida ordinaria está permeada por lo que se percibe en la literatura, arte, cine, revistas, televisión, comerciales y periódicos; a través de ellos se constituyen códigos visuales que se registran en la memoria y que en determinado momento se representan consciente o inconscientemente en el acto fotográfico. El registro en la memoria contribuye a integrar un bagaje visual que está en relación con experiencias culturales personales, para luego representarlos en fotografías, así de esta manera el fotógrafo desempeña el rol de filtro cultural (Kossoy, 2014: 147).

Lo que también se discute en el texto es la postura que adopta el fotógrafo como filtro cultural y cómo a través de la fotografía documental trascendental se acerca al "otro", particularmente al marihuano no visibilizado o percibido como "otros" con hábitos sociales perniciosos y de "malas costumbres", lo que para Goffman (2006) constituye "una teoría del estigma, una ideología para explicar su inferioridad y dar cuenta del peligro que representa esta persona" (p. 15). 


\section{LA FOTOGRAFÍA DOCUMENTAL TRASCENDENTAL. EL FOTÓGRAFO COMO FILTRO CULTURAL}

Joan Fontcuberta (2016) define la fotografía documental transcendental como el fruto de un contacto entre la realidad externa y el espíritu interno (p. 45). La sensibilidad es vital para la fotografía, sin ella el trabajo fotográfico es hueco y frío. La fotografía documental permite ver la estética cotidiana, apreciar lo prosaico, lo feo, lo banal, lo raro, lo incomprendido, como algo bello y digno de reconocerse y mirar. Mandoki (2008) comenta sobre la sensibilidad y cómo se manifiesta según condiciones bioculturales, perceptuales y valorativas, condiciones que tradicionalmente nos han llevado a capturar lo que se considera estéticamente bello ${ }^{3} \mathrm{y}$ digno de observarse. Sin embargo, la fotografía documental trascendental abre su lente a lo que la misma autora denomina estética prosaica, y a partir de la estesis ${ }^{4}$ el creador la liga a su forma de observar el mundo. Experiencia personal que lleva al fotógrafo a la otredad e identificarse con los personajes que capta mediante el acto fotográfico.

La fotografía es "herramienta de exploración de la sociedad" (Becker, 1974 citado por Suárez: 13) que permite observar otras realidades y cruzar fronteras sociales, culturales o políticas a partir de la historia que se busca narrar a través de la lente. En este sentido "la fotografía se convierte en un material privilegiado para observar cómo los valores de clase pueden trasmitirse aún sin ninguna educación" (Bourdieu, 1979 citado por Suárez: 35).

Antonio Prieto (2019) dice que "la poética de la frontera se vale de un lenguaje poético tanto en sus manifestaciones literarias

3 Centrar nuestra mirada en lo que es considerado bello nos pone frente a un problema, en palabras de la misma Katia Mandoki, desarrollamos el Síndrome Pánglos: solo tratar con lo bueno y hermoso de las cosas, es decir se ocupa solo del arte y lo bello, teniendo como referente lo "bello occidental europeo" como "lo bello universal" (Mandoki, 2008). Este síndrome muestra un problema etnocentrista al negar lo "otro" por considerarlo no bello y relacionarlo al pobre, mientras al blanco se le piensa como bello, leal, exitoso, etc.

4 Mandoki la define como "sensibilidad o condición de abertura, permeabilidad, o porosidad del sujeto al contexto en que está inmerso, en tanto expuesto a la vida” (2008: 67). 
como visuales". Ser fronterizo (en el sentido de vivir en Ciudad Juárez) permite de alguna manera constituir una poética visual en lo prosaico, en las periferias y sus contextos sociales y que otros fotógrafos no se atreven a mirar porque de alguna manera transgreden. ${ }^{5}$

Sontag (2018) explica cómo la imagen fotográfica procura pruebas de algo que se conoce de oídas, pero dudamos, y parece demostrado cuando nos enseñan una fotografía. Pero hay que recordar que la foto no necesariamente muestra lo que es real, sino lo que ha sucedido frente de ella, pero ¿qué es lo que sucedió en ese encuadre?, dependerá por un lado del azar dentro de lo cotidiano y por otro del bagaje cultural del sujeto que opera la cámara: su experiencia y posición ante la vida impregnan la fotografía. Estas posturas develarán la episteme del discurso visual que al último se revelará en la fotografía-objeto. ${ }^{6}$

El fotógrafo posee artilugios retóricos para diseñar datos y dibujar contextos, así se tiene a la composición, los encuadres y la luz. Junto a estas herramientas se transmite un mensaje en la fotografía. Estas herramientas estéticas, utilizadas en el encuadre fotográfico, dependerán del bagaje de cada fotógrafo para que puedan ser empleadas como parte de la composición y no dejarlas al simple azar para confirmar la hipótesis de que los fotógrafos somos un filtro cultural (Kossoy, 2014: 147).

5 Sin embargo, se considera muy necesario cuestionarnos más sobre las fotografías que vemos y no solo aceptarlas por "bonitas", ya que tal vez en una foto que nos rehusamos a observar por considerarla fea, vulgar, prosaica, o de mal gusto por tocar temas que no son gratos para algunos, en realidad podría darnos información nueva, útil en algún tema de interés, pero ello dependerá de nuestra capacidad para decodificarla; es decir, poder leer la imagen y descifrar lo que hay dentro: "para extraer el contenido de una imagen, no basta con observarla con pasión. Se debe proceder sociológicamente construyendo un proyecto, acudiendo para ello a la teoría, al método y buscando dilucidar un problema empírico concreto. A este proceso de creación de conocimiento a partir de una foto es que llamamos sociología visual" (Suárez: 10).

6 Aunque el significado de una fotografía también depende de la lectura y comprensión por parte del receptor de la imagen, es decir, quien la ve, quien la consume; aquí intervienen varios factores como "... los sociológicos o los símbolos convencionales o accidentales, de tal forma que el lector necesita algunas herramientas culturales y conceptuales que le ayuden en la decodificación del texto fotográfico" (Gómez citado por Irala, 2011). 
La fotografía, para ser observada sociológicamente, debe atravesar por un procedimiento particular que la ubique como objeto analizable. En este sentido, se considera en primer término que una fotografía es un producto cultural, por tanto, responde a un agente social que la emitió y cuya visión del mundo quedó plasmada en ella más allá de la voluntad del propio autor y "detrás de la cámara se encuentra siempre el ojo culturalmente interesado del fotógrafo quien selecciona y enfoca desde un ángulo determinado una realidad previa: lo fotografiable, lo que se desea fotografiar, lo que se puede fotografiar" (Giménez citado por Suárez, 2008: 24).

Kossoy (2014) señala que las fotografías que "el fotógrafo" considera como "personales" son las que suelen mostrar de mejor manera su postura ante la vida y el mundo. Esto nos hace plantear ¿por qué ese valor personal ante dicha escena por parte del fotógrafo? y ¿qué nos puede reflejar de esta cotidianidad que se observa?, ¿qué nos pueden decir sobre el autor que las toma? Sin duda la respuesta abundaría respecto del conocimiento y el proceso creativo del fotógrafo.

De esta manera se acerca a la cotidianidad desde la estética prosaica, esa que permite reconocer estos lugares ignorados o poco vistos. Apreciar lo prosaico es necesario para el fotógrafo documental, lleva a conocer otros personajes y realidades del entorno social, por tanto, "la fotografía constituye la metafísica de esa cultura visual actual. Este papel convierte los resultados de la cámara en productos que nos ayudan a entender metafísicamente esa cultura y movernos en ella" (Josep Ma. Casdemont por Fontcuberta, 2016: 13). La estética prosaica permite ampliar conocimiento de alguna manera al preguntarnos “¿Qué tal si...?”, es decir, el ¿What if? que expresa Katya Mandoki (2008) para preguntar qué se podría aprender del personaje de la calle. Y para trascurrir en estos mundos es fundamental el caminar en la urbe como parte del proceso creativo. 


\section{EL CAMINAR URBANO COMO PARTE DEL PROCESO CREATIVO FOTOGRÁFICO}

El caminar origina el proceso creativo que lleva a experimentar lo cotidiano de maneras diferentes, para detonar pensamientos y sentimientos que el fotógrafo traduce en textos y fotografías.

Después de haber cursado el taller "El arte y espacio público" en la Universidad de Chile (2017) aprendí a ver la calle como escenario de lo fascinante, en donde tomamos consciencia del mundo personal y del colectivo, lo que me ayuda a entender el espacio público de mejor manera para empezar a experimentar con esta intervención urbana.

Los situacionistas (que interpretan los hechos existentes) pretendieron perderse como forma de dejarse sorprender e influir por los distintos acontecimientos surgidos durante sus derivas. Forma de analizar el urbanismo y el espacio público de una manera transgresora, explorar la ciudad desde sus lados ocultos. El "flaneur" de Baudelaire introduce una postura que explora al sujeto que camina la ciudad y traza el itinerario - un discurso- en el discurrir del paseo que "ordena, para el sujeto, el caos de la ciudad, estableciendo articulaciones, junturas, puentes, entre espacios y acontecimientos desarticulados" (Cuvardic, 2009: 22). Vagar en la calle de una manera creativa permite experimentar la vida misma.

El estilo de caminar y vagar a la deriva nos lleva de cierta manera al periodismo "gonzo", propuesto en el New Journalism, que asume influencias narrativas del movimiento Beat de los años cincuenta. Angulo (2011) expresa que "dentro del gonzo se utiliza una escritura desinhibida autobiográfica, poco estructurada y de aparente descontrol narrativo".

J.M. Servín (2014) sostiene que el periodismo gonzo trasplanta los principios del surrealismo al reportaje, es decir, escritura automática sin correcciones racionales que se expresan en emociones y estados de ánimo y nunca sigue un razonamiento lógico. Este estilo de periodismo evoca una descripción maniática y subjetiva de un evento que convierte al reportero, casi siempre, en un desquiciado protagonista de los hechos narrados. Es preponde- 
rante el ambiente por encima del hecho mismo o del dato duro. El periodismo gonzo es una forma de hacer investigación basada en la práctica (IBP). ${ }^{7}$ Carrillo (2015) explica sobre la investigación basada en la práctica que "uno de los métodos más importantes dentro de este tipo de investigación es la contextualización del tema de estudio desde la perspectiva del sujeto. Es decir, se analiza el proceso de producción de un artefacto mediático como el cine, video, fotografía, multimedia, música, teatro, escultura o instalación, desde una postura subjetiva”.

La estética prosaica sensibiliza y educa al ojo fotográfico para ver a los personajes bellos en lo cotidiano, para encontrar sus historias. Se experimenta la escena para sensibilizar al periodista y al fotógrafo. Este estilo de periodismo permite vivir la vida y entenderla a la par de los etnógrafos con su trabajo de campo. Es hacer investigación participativa porque se forma parte de la historia. La intuición y el sentido del humor ayudan a sensibilizar y observar la vida de manera diferente a lo cotidiano, es un aprendizaje, "el humor es una herramienta para la narrativa documental” (Jorge Ayala. Comunicación personal, 2019).

\section{EL TEMA}

Seleccionar el tema, como fotógrafos, se traduce en la posible elección de fragmentos imaginarios que pueden ser capturados de la realidad. El diseño, el tema y la fotografía se funden e integran la foto narrativa como tratamiento estético individual, "basta con ser lúcido respecto a lo que ocurre y ser honesto respecto a lo que uno siente. En definitiva, basta con situarse en relación con lo que se percibe" (Cartier, 2017: 20). La honestidad conduce a analizar cómo nos identificamos con el sujeto y/o tema para estar en contacto con la escena y encontrar ese momento, aquel fragmento que se congela en la fotografía y en la memoria.

7 IBP: La investigación basada en la práctica existe como género metodológico desde los inicios de la década de los noventa y ha sido un fenómeno creciente desde entonces, siendo cada vez más común en las instituciones de enseñanza superior; este modelo ha crecido principalmente en las artes y las humanidades (Carrillo Quiroga, 2015). 
Ser fotógrafo permite abordar temas tabúes para mostrar pequeños guiños de estas realidades sociales, hay que observar las calles como si fueran escenas de teatro con personajes. Esta manera de fotografiar visualiza el acto creativo de lo cotidiano en la calle o en el campo de trabajo. Las fotografías se capturan siempre con respeto hacia la persona fotografiada y "allí tienes que sonreír, pero nunca reírte, pues lo interpretaran como burla, debemos de ser invisibles" (Cartier, 2015: 30-31).

\section{EL REPORTAJE Y LA INTERVENCIÓN URBANA. LA ESTIGMATIZACIÓN DEL MARIHUANO}

Se realizaron once intervenciones urbanas de 2017 a 2019. ${ }^{8}$ Las intervenciones urbanas fueron a partir del foto-reportaje. Hipotéticamente se planteó que el marihuano es portador de un estigma en Ciudad Juárez. La intervención se ejecuta a partir de la fotografía documental para un manejo creativo de lo cotidiano y respeto hacia la persona capturada por el lente de la cámara y de igual manera con el tema.

Trabajar en algún reportaje es reflexionar sobre el tema, hacer esto es importante para conseguir una buena edición del trabajo, así lo señalan Fox \& Caruana (2014). Reflexionar es dirigir la mirada retrospectiva sobre el hecho hasta el momento analizado, reconsiderar y cuestionar los pasos dados y el porqué. El proceso creativo del fotógrafo consiste en que cada fotorreportaje revela una postura única de aquella realidad, pues “cada fotógrafo tendrá un método o sistema distinto de recopilar la investigación. No existe una forma correcta o incorrecta de hacerlo, sino que cada uno debe hallar el enfoque que mejor funcione" (Fox \& Caruana, 2014: 109).

Hay que romper la rigidez con la que se suele querer retratar la vida. Hay que disfrutar y divertirse, pues se considera que el documental es "el tratamiento creativo de la realidad" (Grierson citado por Platinga, 2014: 32). La fotografía y el acto fotográfico deberían caracterizarse por una esencia de rebeldía. Un acto rebelde

8 Para fines de este trabajo, únicamente hará referencia a dos. 
debe ser parte del fotógrafo, una insubordinación visual por mirar. Se tiene que hacer más fotografía desde una postura social que lleve a la reflexión bajo el ojo del fotógrafo como filtro cultural, que con su cámara como arma dispara dentro de su cotidianidad. Hay que ser observador, cauteloso, pensativo y reflexivo para acertar el momento indicado de presionar el obturador.

"El reportaje es único" (Mario Luna, conversación personal, CUEC, 2019) porque quizá a través de él se descubre algo que hace cambiar de opinión o de enfoque. El reportaje es una experiencia de vida que por el ojo fotográfico y la sensibilidad se puede representar de varias maneras: escrito, visual o audiovisual. Así, las imágenes empiezan a recrearse dentro de la mente, como una manera de archivo visual que se queda impregnado de las fotografías y de los momentos que, cargados con emoción, se distinguen de otros. Esta carga emotiva es vital para el fotorreportaje.

Los diarios de campo, los informantes, las entrevistas informales, los relatos de vida, la fotografía, la escritura y la grabadora de audio, son herramientas que permitieron recopilar las experiencias del movimiento cannábico y dieron pauta para una intervención urbana. Todas estas herramientas del periodismo sirvieron para escudriñar la cotidianidad de la cultura cannábica mexicana.

En este trabajo, el fotorreportaje parte de un análisis a la imagen negativa ${ }^{9}$ que se le ha asignado al consumidor recreativo de cannabis en México. Este personaje popular de "El Marihuano" ha sido representado de distintas formas a través del tiempo, pero todas comparten algo en común, el imaginario social ${ }^{10}$ creado alrededor del fumador de cannabis. Suárez (2008) comenta que la fotografía ha sido utilizada como un objeto "provocador" en discusiones y de análisis. Tal es el caso de ser utilizada como herramienta para la documentación etnográfica para registrar la realidad en la investigación de campo.

9 Imagen negativa: Atributo desacreditador (Goffman, 2006). Todos aquellos atributos desacreditadores que los anglos y el español han elaborado sobre el mexicano se ven dentro del "marihuano".

10 Imaginario social: Conjunto de las representaciones que un grupo social o un individuo construyen sobre el mundo. Son representaciones que estos tienen del mundo y de sus valores (Goffman, 2006). 
El hilo conductor de este trabajo fue la imagen del personaje "Juan el Moto" en el libro Yerba, goma y polvo, de Pérez Montfort (1999), en la que se observa a un consumidor de marihuana.

La postura sociológica que llega a tener la fotografía presentada por Suárez (2008) hay que destacarla para analizar al marihuano como personaje de interés en esta investigación la cual utiliza el periodismo gonzo y experimenta con la intervención del espacio público por parte del fotógrafo. La postura teórica para identificar a nuestros sujetos es a partir del estigma social de Erving Goffman (2006) que identifica las deformaciones físicas, los defectos de carácter del individuo y los estigmas tribales de la raza, la nación, y la religión. El consumidor de cannabis en México encaja en las características del estigma social presentadas por Goffman y en esta investigación se le observa con lo indígena, mestizos de los bajos mundos de la calle que son calificados como: "los vagos", "los léperos", "los grifos", "los marihuanos", personajes anónimos populares.

El personaje de "Juan el Moto" lo reconocemos por una fotografía de Víctor Casasola en el citado libro de Pérez Monfort. La imagen presenta a un personaje anónimo que se encuentra en cuclillas, en ropa interior de la época, piel morena, pelo negro, con un paliacate en el hombro derecho, descalzo y sosteniendo la mirada a la cámara mientras le da una bocanada a un cigarrillo de marihuana, "un gallo". 


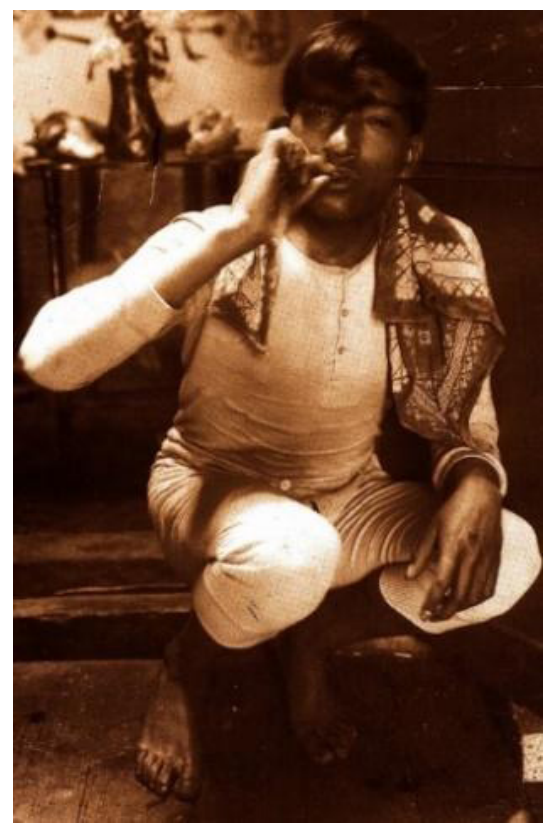

Fotografía 1. Extraída de Yerba, goma y polvo, de Pérez Montfort, 1999.

El periodista cannábico mexicano Juan Pablo García Vallejo postula la teoría de los consumidores recreativos del cannabis y los identifica como originarios del Barrio de La Merced en la Ciudad de México, a estas personas se les mira y se les señala de manera despectiva como "léperos". Gracias a Ana María Prieto se entiende que "El lépero es el hombre pobre de las ciudades, minas y obrajes del México central en los siglos XVIII y XIX; pero también hasta tiempos de la independencia, es miembro de las castas, y, por tanto, distinto del indio, como tal" (Hernández, 2005: 102). También se le conoce como el "grifo", que el diccionario de la Real Academia Española lo describe así: "persona con el pelo enmarañado, crespo, embriagado por la bebida o la marihuana”. Las pulquerías son los lugares en los que encaja el "grifo", asimismo también el revolucionario mexicano. Después de todo, era la gente del campo la que se enlistó en los ejércitos de Zapata y Villa. 
Al revolucionario se le asocia como una figura romántica y nacionalista, pero al "grifo" se le estigmatiza por su consumo de cannabis en sectores indígenas y pobres. Así se moldea

...la identidad que se construye a partir de la confrontación del ideal del yo individual y del ideal social. Por esa causa, el proceso de construcción de identidad tiene sentido y un origen que está íntimamente relacionado con los valores, principios y cultura del ambiente y es, indudablemente una construcción social (Falcón, 2008: 2).

El síndrome Pánglos es una influencia para desprestigiar a estos personajes populares por considerarlos "feos", "malos", por el europeo de la conquista española. Al consumidor de cannabis se le agregan otros atributos desacreditadores que moldean una persona floja, pobre, y en ocasiones "pecador", se le dice que es vicioso, criminal, loco, en consecuencia, un riesgo para la sociedad. Los conservadores le dicen hippie, le llaman "chairo". Esta construcción social asociada al consumidor de cannabis parte del calificativo "vago". Con Porfirio Díaz se origina el Tribunal de Vagos, que persigue a desempleados y falsos mendigos, a hombres fuertes y sanos que no ejercían oficio, y a aquellos que vivían de ingresos familiares pero que se dedicaban a la "mala vida" del juego y la ebriedad, por tanto, eran tipos ideales para ser arrestados.

García Vallejo (2017), en el V Congreso de Sustancias Psicoactivas por parte de la UNAM, afirmó que “... la figura del soldado marihuano domina toda la primera parte del siglo XX en México, cualquiera te va a decir, nuestra mamá, nuestra abuelita, el sacerdote, el periodista dicen, "marihuana es el soldado"'. Hacia 1950 los jóvenes van a diversificar la figura del marihuano pues se les identifica como rebeldes sin causa, incomprendidos, transgresores de las leyes, poetas, hippitecas (término utilizado por García Vallejo durante su discurso en el Congreso de la UNAM). José Agustín y Parménides García Saldaña representan al marihuano como anclaje para atraer la atención del lector. Esta literatura de los años setenta significa la independencia del marihuano "a pesar de que estaba la prohibición en la literatura no existe tal prohibición, por- 
que todo mundo está fumando, todo mundo está gozando, todo mundo está pasándola bien, pues para eso la mayoría de la gente fuma marihuana, para pasársela bien, para quitarse el estrés" (J. P. García Vallejo, UNAM, comunicación personal, diciembre 2017).

El consumo de las drogas no es privativo de los barrios bajos, pobres y olvidados, también lo es de la clase mediera y de alto ingreso (económicamente hablando), las drogas no discriminan clases sociales.

El fotógrafo como filtro cultural permite visualizar este mundo tabú de consumo de sustancia ilegales. La fotografía de "Juan el Moto" (fotografía 1) es la guía para retratar al "Poblano" (fotografía 2), en ambas vemos la postura de agarrar con los dedos el cigarrillo de marihuana, "el porro", manera peculiar de sostener el carrujo de mota con el dedo índice y el pulgar, posición icónica que sirve para identificar el consumidor de cannabis.

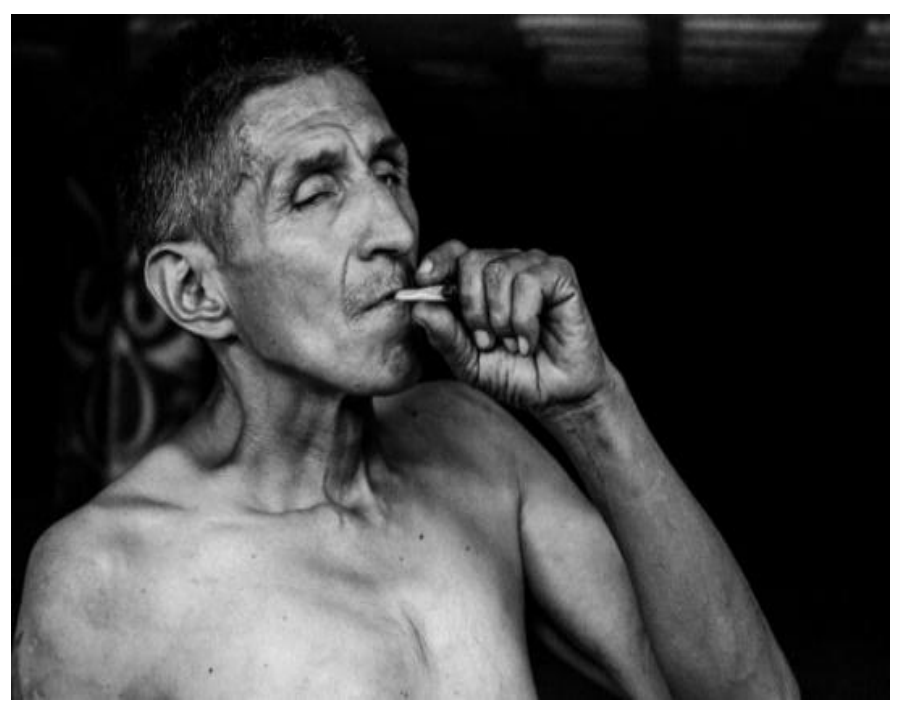

Fotografía 2. Por Francisco Servín. "El Poblano”.

En la fotografía se reflexiona el miedo o desacreditación que conforma el imaginario social que estigmatiza a este personaje 
conocido como "el marihuano". El retrato de El Poblano ${ }^{11}$ es la fotografía empleada en la intervención urbana; aquí se comparte el espacio con él, una persona en situación de calle que bien podría decirse que representa al "lépero".

El Poblano habita de repente en un edificio en obra negra ubicado por Plaza de las Américas en Ciudad Juárez. Acude a este no lugar $^{12}$ para resguardarse del clima mientras algunos otros llegan a compartir estas tapias con él. Utilizan el espacio para pintar graffiti, beber cerveza (caguamas) y darse unos toques.

Es ese personaje que origina miedo, asusta por su aspecto. Es alguien olvidado que vive en la calle paseando, sobreviviendo, un fantasma, un nómada de esta ciudad. Representa al "vago", por eso tiene fuerza su retrato "dándose las tres", porque carga y refleja todo el estigma social y en un instante lo comparte con "Vroma", el joven con el cual comparte el porro (fotografías 3 y 4). Dos generaciones muy distintas compartiendo un "gallo" y el estigma social.

11 Una persona en situación de calle, adicto a la heroína. Un fantasma de la sociedad que pasea sin rumbo la urbe y que en ocasiones se llega a refugiar en estas tapias, las cuales comparte en ocasiones con jóvenes que visitan este lugar para pintar graffiti, tomar cerveza y echarse unos toques.

12 La hipótesis que es defendida al hablar de los "no lugares" es que "la sobre-modernidad es productora de no lugares, es decir, de espacios que no son en sí lugares antropológicos y que, contrariamente a la modernidad baudeleriana, no integran los lugares antiguos: estos, catalogados, clasificados y promovidos a la categoría de lugares de memoria', ocupan allí un lugar circunscripto y específico. Agreguemos que evidentemente un no lugar existe igual que un lugar: no existe nunca bajo una forma pura; allí los lugares se recomponen, las relaciones se reconstituyen; las "astucias milenarias" de la invención de lo cotidiano y de las "artes del hacer" de las que Michel de Certeau ha propuesto análisis tan sutiles, pueden abrirse allí un camino y desplegar sus estrategias. El lugar y el no lugar son más bien polaridades falsas: el primero no queda nunca completamente borrado y el segundo no se cumple nunca totalmente: son palimpsestos donde se reinscribe sin cesar el juego intrincado de la identidad y de la relación" (Augé, 2000: 83-84).

13 El Vroma: joven que conozco durante la investigación. Rapero, graffitero, rebelde, irreverente ante la autoridad. Su padre fue arrestado en Estados Unidos, situación que detona un odio de Vroma al sistema de migración estadounidense. 


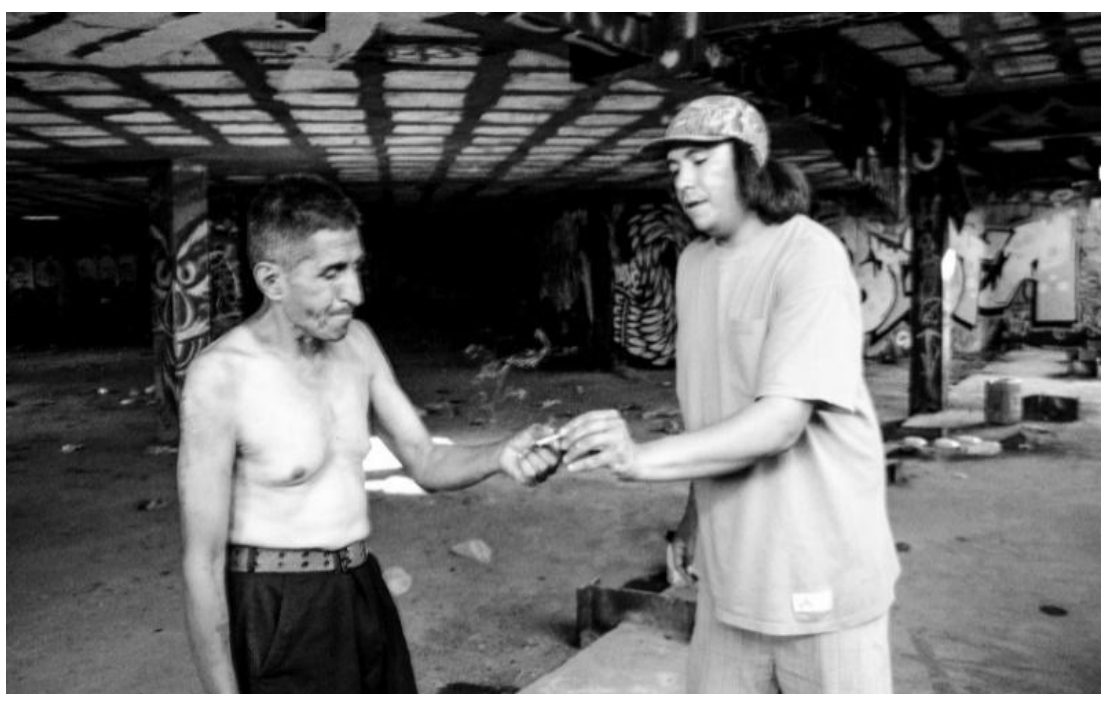

Fotografía 3. Por Francisco Servín. "Vroma dándose un toque con El Poblano en Under”. Ciudad Juárez. 2017.

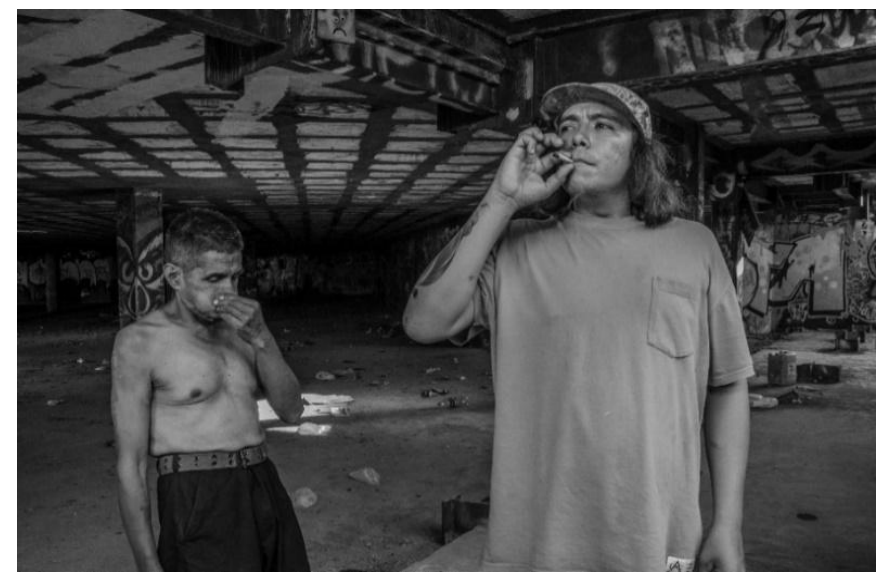

Fotografía 4. Por Francisco Servín. "El Poblano compartiendo un porro con Vroma en el Under”. Ciudad Juárez. 
Un relato de esa tarde por parte de Vroma: ${ }^{14}$

Me dicen en la calle Vroma, con "v", tengo 24 años, carnal, ya mero cumplo los 25... sigo vivo, es lo bueno. Bueno aquí es un hotel abandonado que creo que me habían dicho que del "Greñas", un pinche narco bien pesado y creo que no la armó y quedaron aquí las tapias y descubrimos que aquí podíamos pintar y pistear, pasarla chida sin que nos moleste la policía.

Para mí es un pinche estilo de vida, pero igual conoces bandera chida en todos lados, pero lo del estigma que te digo es porque me puedo subir a la ruta recién fumado un "joint" todo apestoso y luego todas las señoras voltean a ver como si dijera... no sé... la mirada esa fea... la de la abuelita esa que dice "mmm... otra vez están quemando". Para mí eso es un estigma. Te marca... igual ninguna pinche vecina me habla, igual no hay problema, pero pues... respeto. Yo respeto. Igual yo, digo si voy caminando por el parque y veo niños, pues lo apago el gallo, intento de respetar todo eso.

No es relacionarlo al narco... bueno, simón, los narcos pueden comprar sus armas por esto, eso una vez me lo dijo un policía, "qué no ves que por esto compran sus armas para matar a nosotros y a la gente...", un rollo bien culero, pero igual y sí, pero es la realidad. ES Juárez, para mí Juárez fue fundado por lo ilegal. Para mí ahorita la policía está... como que están muy fuertes en sus prejuicios. Te ven culero, te ven como un delincuente nomás por fumar, wey... es como que está mal. No me hace sentir mal, pero igual son los pinches estigmas que siempre van a estar.

Pinche chota, me para y le pregunto por qué. Y me dice que me veo sospechoso. ¡No mame! Y el wey que va en la troca con las rolas bien chacas dándose un córner, y yo ahí nomás parado por los pinche olanes, pero pues igual uno vive como quiere y a la verga, wey, la neta (Vroma, conversación personal, 2017).

Partimos de una postura epistémica que considera que la fotografía es para todos y también tiene que estar en la calle y contraponer estas visiones idealistas de la publicidad. La fotografía

14 Video del relato de Vroma: https://www.youtube.com/watch?v=SlkIPOqOO48\&t=3s 
puede filtrar la censura en los medios y en los espacios públicos. Es un medio para poder representarse, para reconocer al otro, darle voz y reapropiarse del espacio público. De la fotografía documental Cartier Bresson (2017) afirma que "La anarquía es una ética” (p. 12). Es un acto rebelde de observar donde los demás no se atreven a ver.

\section{Las intervenciones}

Once intervenciones fotográficas en el espacio público para documentar el estigma social. En este trabajo solo se documentan dos: "El poblano" y "Los ojos del marihuano".

\section{"El Poblano"}

En esta intervención se instaló la imagen en diferentes espacios de Ciudad Juárez para que la fotografía sea deteriorada, por el tiempo, el clima y el transeúnte. El objetivo es diseñar un diálogo visual para observar el estigma. Para el fotógrafo la imagen deteriorada es lo que importa, ya que es donde culmina la obra en su retórica visual.

La intervención urbana es ver cómo, en el transcurrir del tiempo, se deterioran las piezas fotográficas. Es de interés el deterioro y la escena efímera en la calle para completar el diálogo visual de la obra. Se buscó lo efímero por ser contestatario e ir contra la perpetuidad de la fotografía. Se piensa en la memoria y en cómo esta también puede ser efímera, porque se desmorona con el tiempo hasta el olvido.

Ante el rechazo de algunas personas, en el proyecto se pensó en poner fotografías en gran formato en la ciudad para que fueran desgarradas por el efecto del tiempo o por el transeúnte que quisiera romper la foto del "otro", es un juego visual para darle sentido a la intervención. La estética del rip, ${ }^{15}$ el desgarrar, trae consigo significados estéticos.

15 Estética del rip: Al hablar de estética dentro del arte nos referimos a la percepción de lo que encontramos bello. El rip es la palabra en inglés que hace referencia a la acción de ser desgarrado. Podemos decir que se busca que la intervención urbana llevada a cabo sea desgarrada y con esto darle un sentido estético, el cual le da una connotación de "bello"en la estética prosaica que aplicamos a la imagen, le da una 
La intervención consistió en pegar tres posters de El Poblano en diferentes espacios, como parte de la experimentación. Estas fotografías se utilizaron para intentar crear una reacción. Se representa a este personaje del imaginario social, que da un cierto miedo a la sociedad por ser "el marihuano" estereotipado.

Las primeras imágenes utilizadas fueron ordenadas por secciones y como resultado se obtuvieron cuatro filas de nueve hileras, para un total de 36 posters tamaño tabloide, para crear la imagen tipo rompecabezas. Se utilizó adherente (engrudo) para pegarla. Después se mejoró la técnica al poder imprimir la imagen en plotter, en tamaño de 1.75 metros de alto por 2.45 metros de ancho.

La primera fotografía en la intervención se colocó en la calle Altamirano, zona centro de Ciudad Juárez (Fotografía 5. Intervención 1). Fue adherida en un muro de una funeraria abandonada.

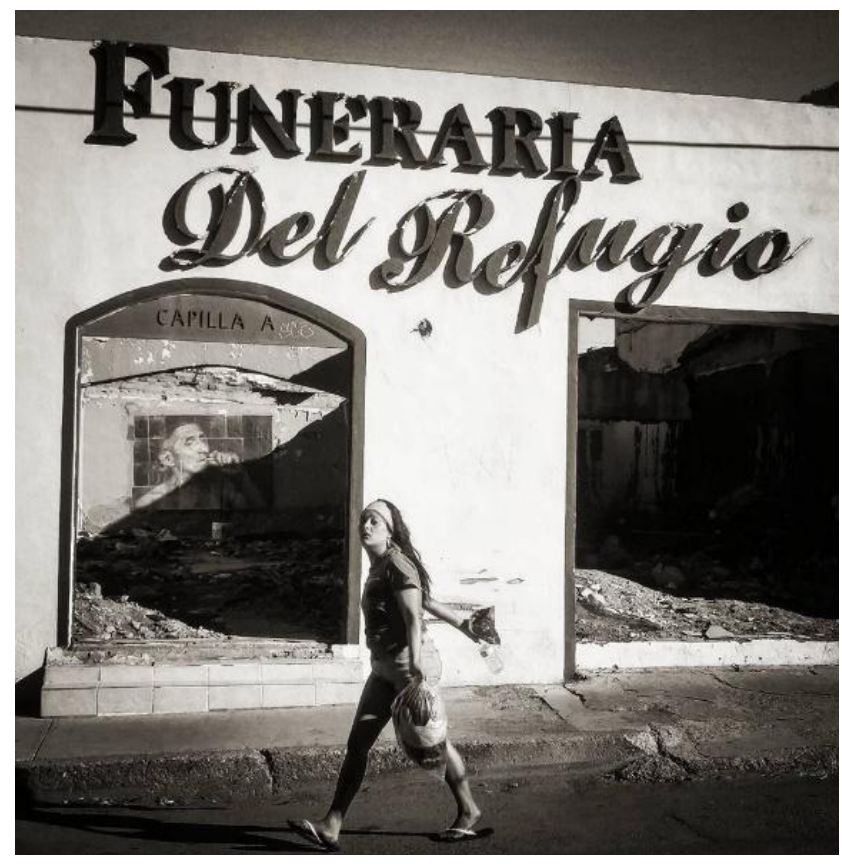

fuerza dentro del discurso visual que se lleva a cabo, el deterioro, la memoria, la representación en el espacio público, la falta de reconocimiento del otro, etcétera. 


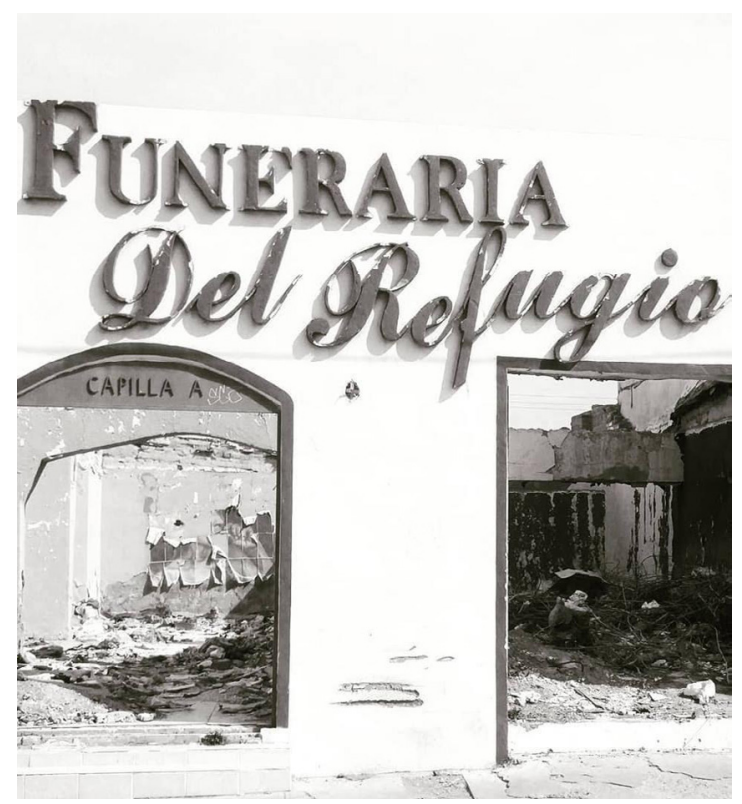

Fotografía 5. Intervención 1.

En la primera toma (fotografía 5) se aprecia la funeraria y una mujer que camina. En la siguiente el sol, la lluvia y el viento fragmentaron la imagen fotográfica que se veía al fondo.

Se eligió este lugar por el abandono de la construcción, acumulamiento de basura y el proceso de destrucción que le ha infligido la mano del hombre. El lugar fue quemado presuntamente por extorsionadores. Las intervenciones se ubicaron en estos lugares por las características descritas y además por el deambular cotidiano de la gente por esas calles. El propósito que se buscó fue la interrelación entre la fotografía y el receptor, sin embargo, las acciones de la naturaleza fueron la casusa principal del deterioro de la imagen (fotografía 6). 


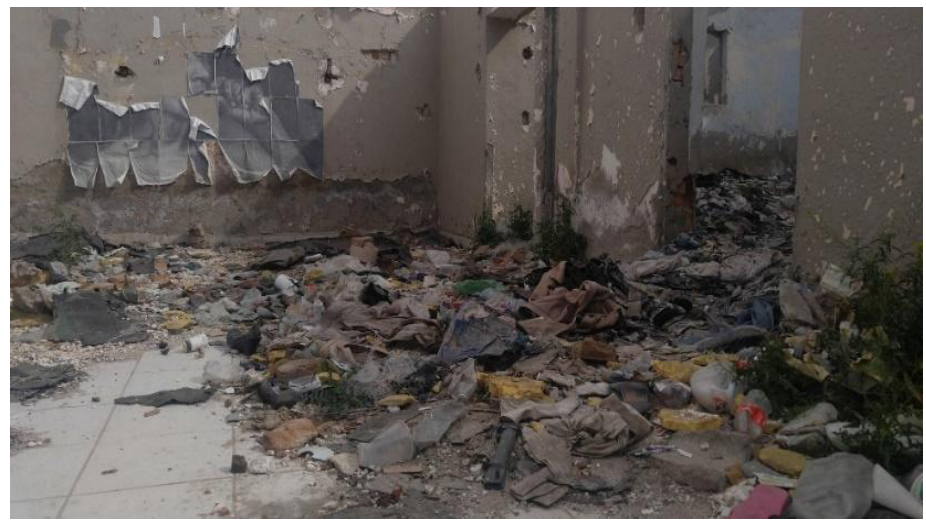

Fotografía 6. Intervención 1.

La segunda intervención fue colocar la imagen de El Poblano en un muro de lo que fue el Hotel Santa Fe, lugar abandonado que se encuentra frente al Mercado Juárez, en la Avenida 16 de septiembre. La pieza mostró su deterioro por acción de la naturaleza, pero también fue intervenida por grafiteros. El lugar fue reactivado como punto de arte urbano después de esta intervención (Fotografía 7). Luego de un año la pared fue limpiada.

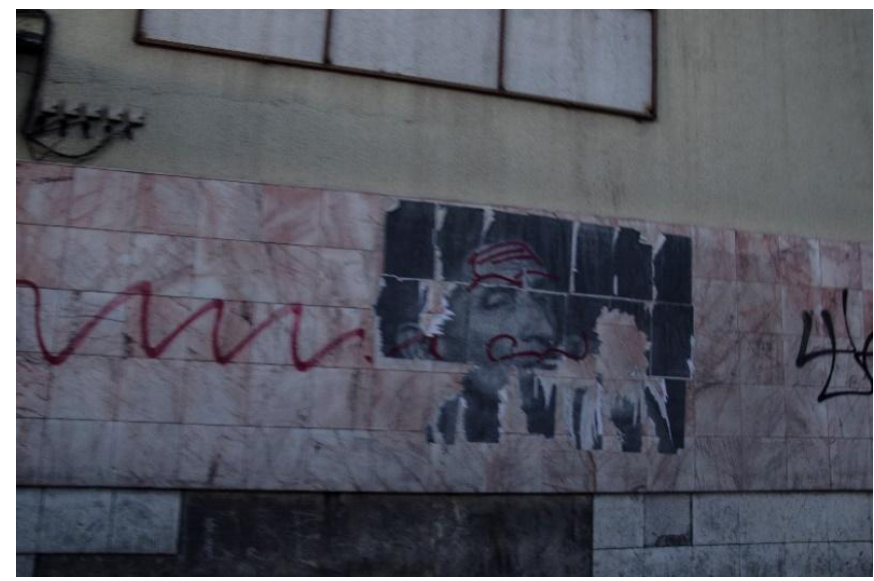

Fotografía 7. Intervención 2. Por Francisco Servín. 


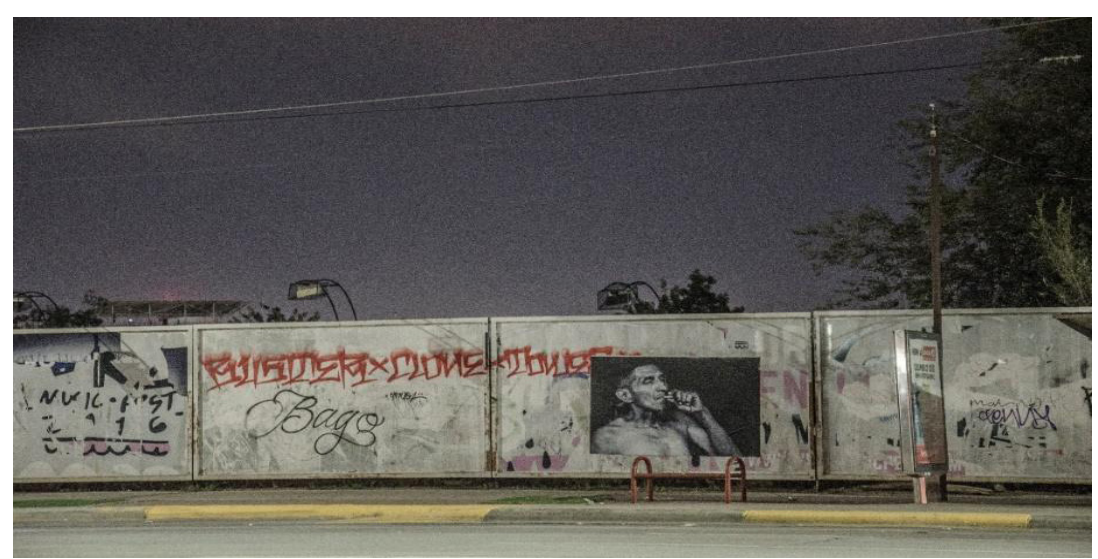

Fotografía 8. Intervención 3. Por Francisco Servín.

La tercera intervención (fotografía 8) se instaló en la Avenida Paseo Triunfo de la República esquina con Avenida de las Américas. En las fotografías 9 y 10 se aprecia cómo el póster se desmoronó y pasó desapercibido para la gente.

El póster durante un mes se mantuvo en su lugar sin ser arrancado hasta que un día amaneció tirado en pedazos en la calle, esto evidencia posiblemente que alguien se sintió ofendido o amenazado arrancándola del espacio público de un día para otro para evitar que sea visto, reconocido, representado.

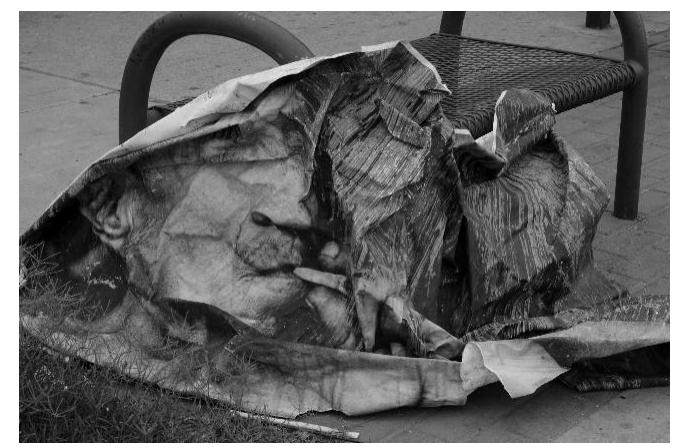

(Fotografía 9. Por Francisco Servín. Ciudad Juárez, 2018. El retrato de El Poblano sobre la Paseo Triunfo de la República. 


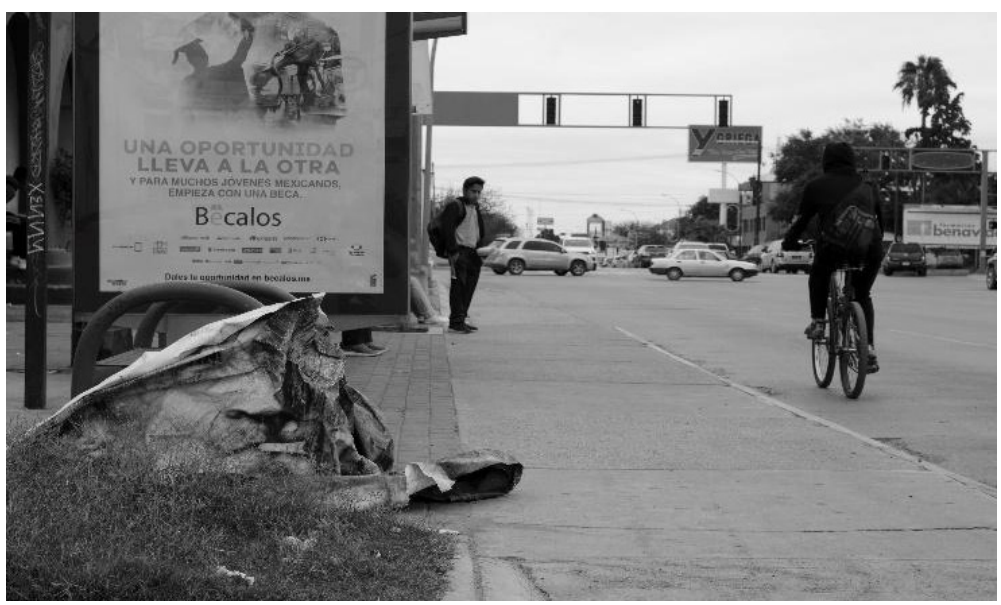

Fotografía 10. Por Francisco Servín. Ciudad Juárez, 2018.

En la imagen anterior vemos el rostro de El Poblano, pero solo se muestra una parte, no obstante, se aprecia la acción de fumar el porro.

\section{"Los ojos del marihuano"}

La segunda exposición (que en realidad fue la novena de la serie) es la que se ha denominado "Los ojos pachecos", que surgió durante la investigación. Los participantes no querían que se les fotografiara fumando un porro porque tenían miedo de revelar su identidad. Por ello el acto fotográfico en su enfoque fue en el encuadre de los ojos, que origina los clichés: "para conocer alguien lo haces a través de la mirada", "los ojos como puertas al alma" y todos esos significados de la mirada y que la gente romantiza. Aquí son ojos marihuanos anónimos, personas que se esconden y evidencian la discriminación social de la cual son víctimas.

Se instalan los ojos de personas en diferentes puntos de la ciudad, jugando con el propósito de generar procesos de significación para que el receptor se pregunte: ¿qué hay detrás de ellos? 

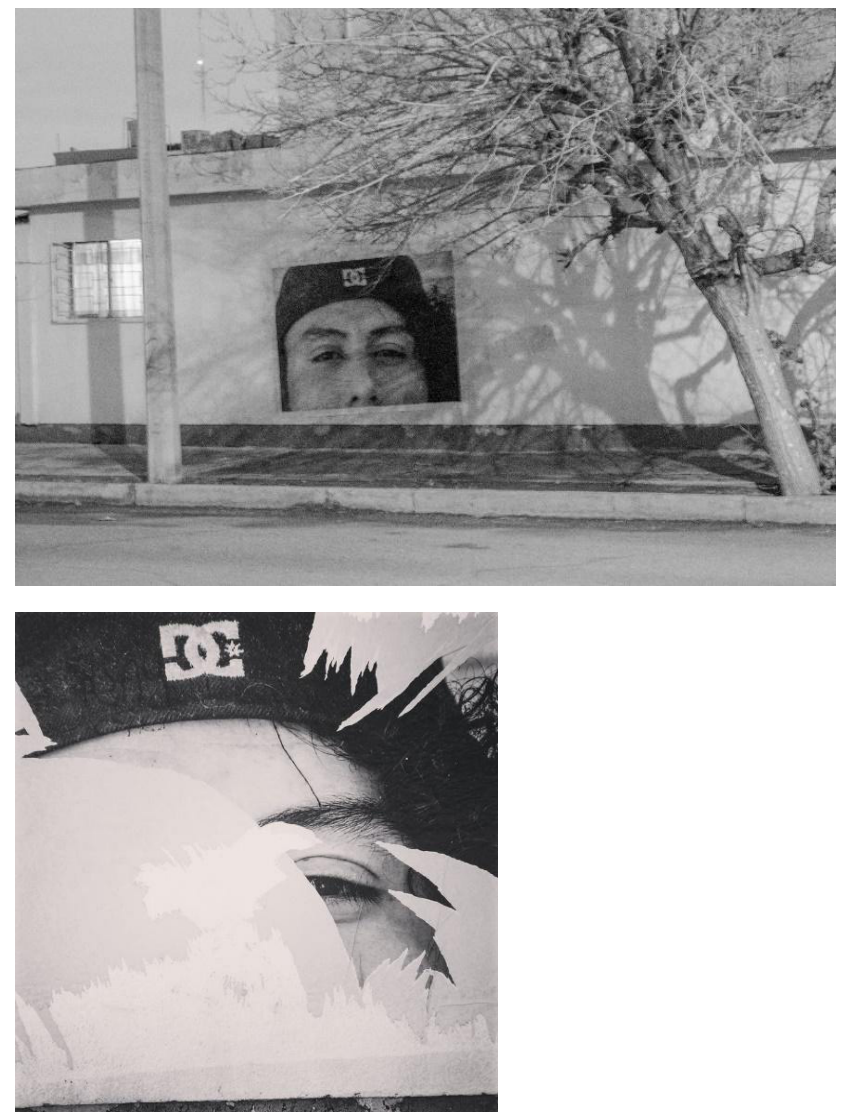

Fotografía 11. Intervención 9. Por Francisco Servín.

Una experiencia mala, pues que amigos les prohíban juntarse conmigo o que nos intenten alejar entre los compas, siendo que no me obligan a fumar ni yo los obligo a ellos. 


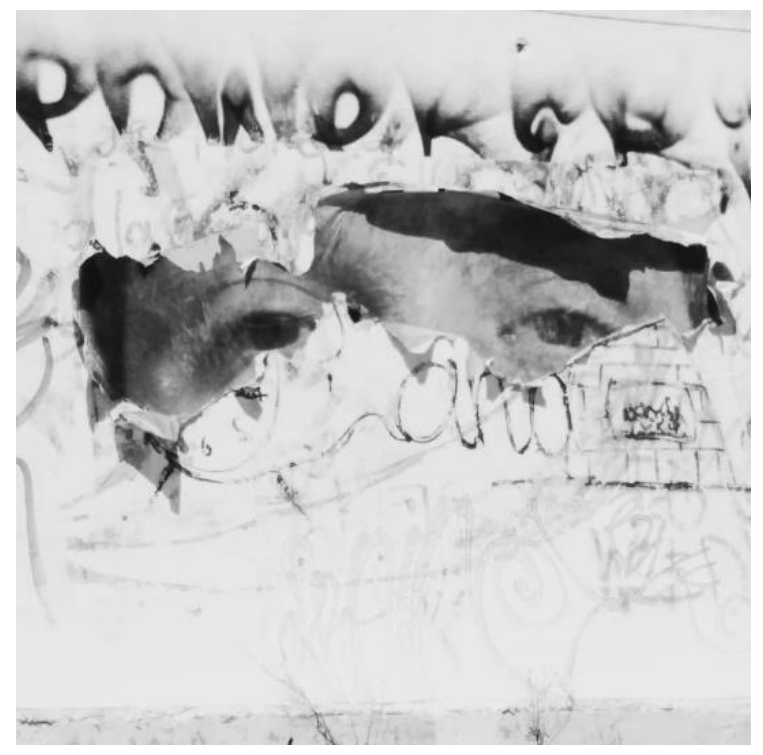

Fotografía 12. Intervención 10.

... Si me lo dice un amigo, pues hasta me da risa y le digo "sí soy", así como muy cínico. Pero si me lo dice alguien que no conozco o que tengo poco de conocer, me siento mal, siento que ya tienen una idea negativa de mí. Como que piensan que no hago mucho de mi vida, como si dejara de hacer cosas por estar marihuano.

En la fotografía inmediata superior se observan unos ojos pachecos. Se colocaron en muros del Under por el Pronaf. Los ojos representan al marihuano anónimo en los "no lugares". La imagen comparte un texto que evita la polisemia. Abajo de los ojos hay un reloj ligado a la palabra "and" y un horno, esto de manera visual hace referencia al juego de la "jerga pacheca”, esta acompaña la frase "Wake and Bake" que se traduce como "despertar y prenderse".

El Under no es solo un sitio de reunión de consumidores de marihuana, también alberga una galería en las sombras, en el olvido colectivo, un abandono a la memoria. Hay negación de la sociedad para esos lugares, para la gente que pinta graffiti, la gente vaga y objeto de descrédito. Al igual que el trabajo fotográfico 
de cualquier autor, refleja su esencia como persona, la cual queda impregnada en su estilo peculiar de hacer la fotografía.

\section{A MANERA DE CIERRE}

¿Cómo puede la fotografía documental incidir en la percepción del estigma del marihuano, mediante una intervención urbana?

La fotografía como documento visual es herramienta metodológica para comprender temas de interés de la sociología y la antropología. Este tipo de trabajo que consiste en la intervención urbana propicia la creatividad. La idea de trabajar la fotografía de una manera diferente integra un conjunto de recopilaciones de relatos personales, que permiten observar al "otro" y su memoria para intentar rescatarla.

Producir obra fotográfica puede ser un proceso complicado. En la fotografía hay que recordar que: "La creatividad es un proceso desordenado, las etapas no se suelen seguir de manera lineal o en una secuencia lógica, sino de la forma que responde mejor a nuestro estilo de trabajo" (Simmons, 2015: 16).

En estas intervenciones se experimentó la práctica fotográfica en el espacio público. Se experimentó a partir de ver la fotografía como parte del sujeto. Como fotógrafo documental, la estética prosaica ayuda a capturar la fotografía en contextos cotidianos múltiples y hace ver otros mundos que los demás no se atreven a mirar por considerarlos no dignos, por creerlos temas "feos", "de mal gusto", mundos prosaicos, obscenos; sin embargo, estas cotidianidades permiten ver a las personas en su esencia íntima, honesta, sin poses.

Aquí destaca la otredad. La fotografía trata de capturar la imagen de la persona desacreditada que desemboca en el estigma; en este sentido, "la poética de la otredad y bajo la premisa posmoderna se avive el construir la "historia" a través de "los otros", las minorías, las subculturas, o las etnias, los usualmente acallados, los vencidos, los colonizados, los marginados" (Mínguez, 2018, comunicación personal). 
La otredad es resultado de un malentendido del concepto de identidad. El otro al referirse al consumidor de cannabis devela quién es en realidad "el marihuano" en México, observardo desde adentro. Falcón (2008) muestra que "el ajeno" es un fenómeno que se da desde el inicio de las primeras tribus para poder sobrevivir, identificando a posibles enemigos.

Actualmente se le quiere responsabilizar al consumidor de drogas de la violencia que experimenta el país por la guerra en contra las drogas. Esta guerra identifica y separa por clases sociales pues se pretende señalar que son los pobres los: violentos, cholos, sicarios y criminales.

La fotografía interactúa con el estigma y con "la poética de la otredad y bajo la premisa posmoderna se avive el construir la "historia" a través de "los otros", las minorías, las subculturas, o las etnias, los usualmente acallados, los vencidos, los colonizados, los marginados" (Flores, 1999; citado por Mínguez, 2018, taller de creación MEPCAD).

Finalmente se concluye que el fotoreportaje se rescatan relatos y se da voz y se observa su mundo, son también textos visuales que reafirman que este grupo social existe y tiene que ser visibilizado. Después de todo la legislación sobre el cannabis en México viene este 30 de abril del 2020.

\section{BIBLIOGRAFÍA}

Cartier-Bresson, H. (2017). Fotografiar al natural. Barcelona: Gustavo Gili.

---. (2015). Ver es un todo. Entrevistas y conversaciones, 1951-1998. Barcelona: Gustavo Gili.

Fontcuberta, J. (2016). Estética fotográfica. Barcelona: Gustavo Gili. Fox, A. y Caruana, N. (2014). Tras la imagen: investigación y práctica en fotografía. Barcelona: Gustavo Gili.

Goffman, E. (2006). Estigma: la identidad deteriorada. Buenos Aires: Amorrortu Editores. 
Hernández Cuevas, M. P. (2005). África en el carnaval mexicano. México: Fondo editorial de la plástica mexicana.

Kossoy, B. (2014). Lo efímero y lo perpetuado en la imagen fotográfica. Ediciones Cátedra.

Mandoki, K. (2008). Estética cotidiana y juegos de la cultura. México: Siglo XXI editores, Conaculta-FONCA.

Plantinga, C. R. (2014). Retórica y representación en el cine de no ficción. México: Universidad Nacional Autónoma de México.

Sontag, S. (2018). Sobre fotografía. México: Penguin Random House Grupo Editorial.

Artículos electrónicos

Arrón, S. (1989). Documentos para el estudio del Tribunal de Vagos, 1828-1848: Respuesta a una problemática sin solución. Anuario mexicano de historia del derecho, (1), pp. 215-235. Recuperado de https://dialnet.unirioja.es/servlet/articulo?codigo=821106

Bolán, E. N. (2001). Reseña de "Acerca la dependencia de la pendenciera e indisciplinada vida de los léperos capitalinos" de Ana María Prieto Hernández. Alteridades, 11 (22), 135-137. [ fecha de consulta 28 de Marzo de 2020.] Disponible en: https:// www.redalyc.org/articulo.oa?id=74702211

Carrillo Quiroga, P. (2015). La investigación basada en la práctica de las artes y los medios audiovisuales. Revista mexicana de investigación educativa, 20(64), 219-240. Recuperado en 28 de marzo de 2020, de http://www.scielo.org.mx/scielo. php?script=sci_arttext\&pid=S1405-66662015000100011\&lng=e s\&tlng=es

Cuevas, M. P. H. (2003). La Virgen Morena mexicana: un símbolo nacional y sus raíces africanas. Afro-Hispanic Review, 54-63.

Castillo Troncoso, A. (2007). La frontera imaginaria. Usos y manipulaciones de la fotografía en la investigación histórica en México. Cuicuilco, 14(41),193-215. [fecha de consulta: 17 de marzo de 2020]. ISSN: 1405-7778. Disponible en: https://www. redalyc.org/articulo.oa?id=351/35112370008.

Cuvardic García, D. (2009). La reflexión sobre el flâneur y la flanerie en los escritores modernistas latinoamericanos. Revista Ká- 
ñina, XXXIII(1),21-35.[fecha de Consulta 25 de Marzo de 2020]. ISSN: 0378-0473. Disponible en: https://www.redalyc.org/articulo.oa?id=44248784002

Falcón, M. I. (2018). Anotaciones sobre identidad y otredad. http:// www.psicopol.unsl.edu.ar/marzo08_01.pdf

Prieto Stambaugh, A. (2017). La poética de la frontera, Amerika [En ligne], 17 | 2017, mis en ligne le 05 janvier 2018, consulté le 16 mars 2020. http://journals.openedition.org/amerika/8331; DOI: https://doi.org/10.4000/amerika.8331

Reseña "Acerca la dependencia de la pendenciera e indisciplinada vida de los léperos capitalinos" de Ana María Prieto Hernández. Alteridades, 11 (22), 135-137. [ fecha de consulta 28 de Marzo de 2020.] Disponible en: https://www.redalyc.org/articulo.oa?id=747/74702211

Suárez, J. H. (2008). La fotografía como fuente de sentidos. Facultad Latinoamericana de Ciencias Sociales. (FLASCO). Costa Rica. https://www.academia.edu/24377165/La_fotograf\%C3\%ADa_ como_fuente_de_sentido?email_work_card=view-paper

Toledo, S. P. (1993). Los vagos de la ciudad de México y el Tribunal de Vagos en la primera mitad del siglo XIX. Secuencia, (27). Recuperado de http://secuencia.mora.edu.mx/index.php/ Secuencia/article/view/436/399 